\title{
Comparison of Three Schemes of Quantum Dots-Based Immunochromatography for Serodiagnosis of Brucellosis in Cattle
}

\author{
${ }^{1}$ Dmitriy V. Sotnikov, ${ }^{1}$ Anna N. Berlina, ${ }^{1}$ Anatoly V. Zherdev, ${ }^{2}$ Saule Z. Eskendirova, \\ ${ }^{2}$ Kassym K. Mukanov, ${ }^{2}$ Yerlan M. Ramankulov, ${ }^{2}$ Kanatbek N. Mukantayev and \\ ${ }^{1}$ Boris B. Dzantiev \\ ${ }^{1}$ Research Center of Biotechnology, Russian Academy of Sciences, \\ Bach Institute of Biochemistry, 119071 Moscow, Russia \\ ${ }^{2}$ Republican State Enterprise "National Center for Biotechnology" under the \\ Science Committee of Ministry of Education and Science of the Republic of Kazakhstan, \\ 010000 Astana, Kazakhstan
}

\begin{abstract}
Three schemes of immunochromatographic serodiagnosis are considered and compared experimentally to determine the specific antibodies that act against the recombinant antigen of Brucella abortus (superoxide dismutase). The considered schemes differ in the order of immunoreagents interacting with the membranes and accordingly in the composition of the detected complexes. As a label, fluorescent nanocrystals were used quantum dots which allow more sensitive detection than traditional gold nano particles. The manufactured test systems were used to test the samples of blood sera of cows with confirmed Brucellosis. The obtained results demonstrated that the highest signal value is achieved in the scheme when the antigen is immobilized on the quantum dot's surface and on the working membrane of the test system and the detected complexes are formed due to the presence of several valencies in antibodies.
\end{abstract}

Key words: Serodiagnosis, quantum dots, immunochromatography, lateral flow immunoassay, superoxide dismutase, Brucellosis

\section{INTRODUCTION}

The methods currently used to diagnose infectious diseases do so, mainly by revealing either the pathogen itself and its components or the immune response of an infected organism to the pathogen antigens (Ryan et al., 2004). The latter type includes methods of serodiagnosis with the determination of specific antibodies in the blood. In some cases, the serodiagnostic approach is preferable to determining the components of the pathogen (Parija, 2014; Tille, 2015) because the humoral immune response is always accompanied by a significant increase in the concentration of specific antibodies in the blood. Therefore, the serodiagnostic approach makes blood a universal probe for diagnosing various infectious diseases.

The serodiagnostic approach is most justified in primary mass investigations. Because the rate of obtaining results is crucial for mass screening, combining serodiagnosis with a simple and rapid method such as Immuno Chromatography (IC) seems promising (Lode, 2005; Wong and Tse, 2009; Quesada-Gonzalez and
Merkoci, 2015; De Puig et al., 2017). IC is based on the flow of a liquid sample along the membranes of a test strip (connected consecutively) with preliminary applied reagents. Contact between the sample and the test strip initiates the reactant's flow and the formation of a detectable complex in the area of the test strip called the analytical or test zone. Due to the maximal pruning in analysis, IC can be performed by unqualified personnel in non-laboratory conditions. As a rule, the duration of IC is 10-15 min. Three main analysis schemes are presently used in the practice of immunochromatographic serodiagnosis (Fig. 1).

During the implementation of the classical scheme of IC serodiagnosis in the course of the analysis the detected complexes are formed of Antigen molecules immobilized in the analytical zone (iAg), specific Antibodies from the sample $(\mathrm{Ab})$ and a conjugate of the label with an immunoglobulin-binding Protein $\left(\mathrm{P}^{*}\right)$. This complex of the $\mathrm{P}^{*}$-Ab-iAg composition is visualized due to the concentration of label molecules in the analytical zone (Fig. 1, Scheme 1) (Schrier et al., 1998; Struyf et al., 1999; Abdoel et al., 2008; Nakano et al., 2015

Corresponding Author: A.N. Boris B. Dzantiev, Research Center of Biotechnology, Russian Academy of Sciences, Bach Institute of Biochemistry, 119071 Moscow, Russia 
(a)

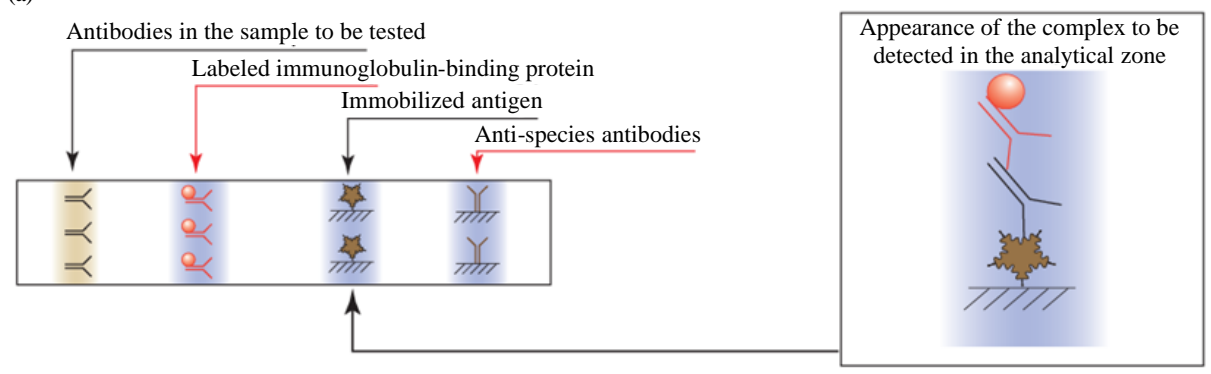

(b) Antibodies in the sample to be tested
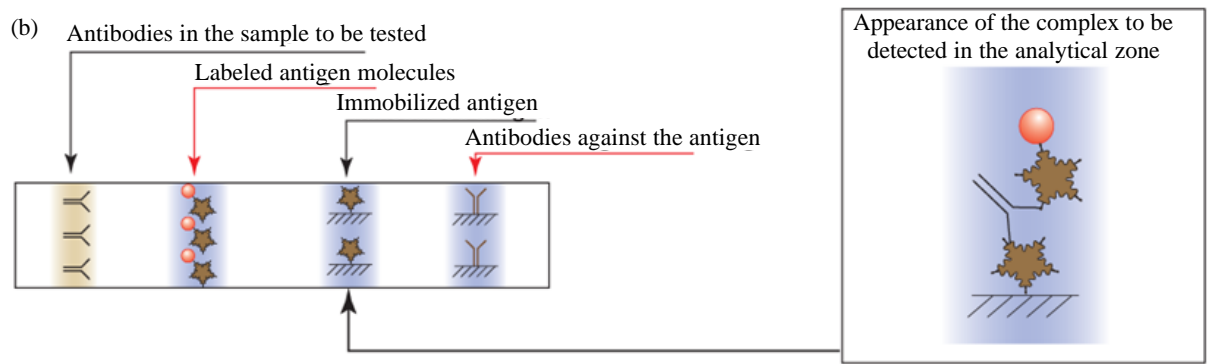

(c)

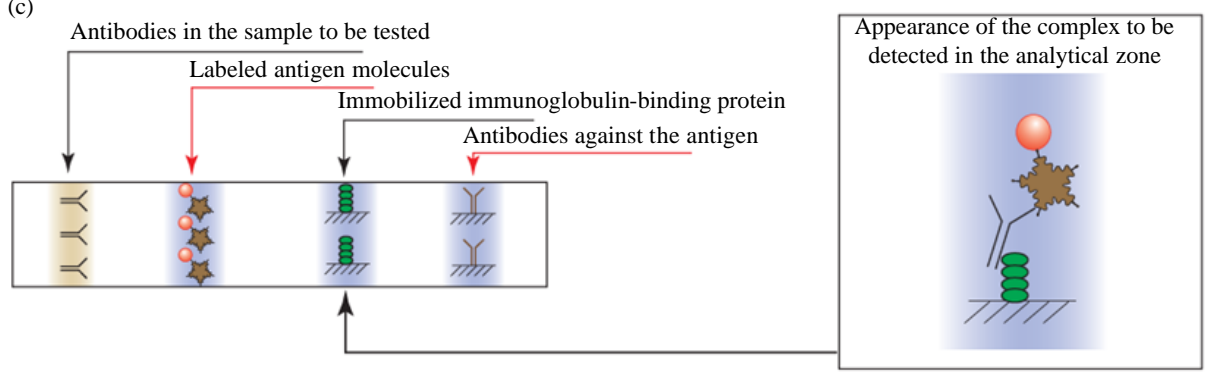

Fig. 1: a-c) The 3 schemes for the implementation of serodiagnosis in IC and the composition of the complexes formed in the analytical zone of the test systems

Sotnikov et al., 2015a, b; Janwan et al., 2016). The vast majority of both those systems described in the literature and commercial test systems for immunochromatographic serodiagnosis are based on the use of this analysis scheme.

In an alternative scheme, the same Antigen is adsorbed onto the surface of the label $\left(\mathrm{Ag}^{*}\right)$ and in the analytical zone (iAg) the detected complexes are then formed due to the presence of several valencies of antibodies $(\mathrm{Ab})$ which leads to the formation of the Ag*-Ab-iAg complex (Fig. 1, Scheme 2) (Sato et al., 2003; Ho-Sheng et al., 2004; Karakus and Salih, 2013; Vrublevskaya et al., 2017).

In the third scheme of IC serodiagnosis, the order of formation of the detected complex is inverted relative to the classical scheme: the label is conjugated with an Antigen $\left(\mathrm{Ag}^{*}\right)$ and the immunoglobulin-binding Protein (iP) is adsorbed in the analytical zone.
Accordingly, the detected complex in this case will be the complex with the composition $\mathrm{Ag}^{*}-\mathrm{Ab}-\mathrm{iP}$ (Fig. 1, Scheme 3) (Rajerison et al., 2009; Ben-Selma et al., 2011; Karakus and Salih, 2013; Sotnikov et al., $2015 a, b)$.

As a rule, the choice of the analysis scheme by developers is empirical and the articles describe the development and application of a single scheme. Only recently have theoretical and experimental comparisons of schemes 1 and 3 appeared in tuberculosis serodiagnosis as an example. These comparisons described in which cases one of the schemes has advantages over the others within the limit of detection (Sotnikov et al., 2018). The situation may vary significantly depending on concentrations of reagents used and the affinity constant of the antibodies for the antigen which follows from the presented data. The theoretical descriptions for scheme 2 are thus, not currently available. It is also 
unclear whether the used marker and other factors affect the choice of the optimal scheme. As a result, the choice of the scheme used is quite random in each new case.

It should be noted that in recent years, replacing traditional nanosized gold nanoparticles and latexes in immunochromatography with other labels detected at lower concentrations has been actively studied. The most popular labels in this regard are Quantum Dots (QDs) composite nanocrystals with intense fluorescence (Goldman et al., 2006; Bruno, 2014; Quesada-Gonzalez and Merkoci, 2015; Taranova et al., 2015; Wang et al., 2015; De Puig et al., 2017). However, today QDs are used for IC serodiagnosis extremely rarely and only in the traditional scheme (Scheme 1) (Yang et al., 2010; Berlina et al., 2013).

The aim of our study included a comparative description of various schemes of IC serodiagnosis with the use of $\mathrm{QD}$ as a label. Accordingly, 3 variants of QD-based IC systems, constructed according to the above schemes were developed for the serodiagnosis of an important infectious disease, cattle Brucellosis. This disease causes severe disability of animal patients and significant damage to agricultural livestock. Therefore, timely diagnosis of Brucellosis is an important task (Minda and Gezahegne, 2016; Nardi et al., 2017).

The recombinant antigen of Brucella abortus, $\mathrm{Cu} / \mathrm{Zn}$-dependent bacterial Superoxide Dismutase (SOD), was used as an antigen in the developed test systems. Periplasmic protein SOD is one of the main enzymes of the antioxidant system of microorganisms which is considered one of the universal mechanisms of the pathogenesis of infectious diseases. Due to its high antiphagocytic activity this protein is involved in the induction of a specific immune response and is considered as one of the most promising antigens for diagnosing Brucellosis (Bricker et al., 1990; Stevens et al., 1994; Tabatabai and Hennager, 1994).

\section{MATERIALS AND METHODS}

The followed reagents were applied in the research: recombinant protein G Streptococcus spp. and peroxidase-conjugated Rabbit Antibodies against cattle immunoglobulins (P-RABIss) from IMTEC (Russia); Tween-20, Triton X-100, sodium azide and 3,3', $5,5^{\prime}$-Tetramethylbenzidine (TMB) from Sigma (USA); $\mathrm{N}$-(3-dimethylaminopropyl)-N'-Ethylcarbodiimide hydrochloride (EDC), Sulfo-N-Hydroxysuccinimide (NHS), and chloroauric acid from Fluka (Switzerland) and albumin from Bovine Serum (BSA) from MP Biomedicals (USA).

The consumables used were as follows: HisTrap columns (Amersham, USA); Ni-NTA Agarose (Invitrogen
Corporation, USA); carboxylated QDs (Invitrogen Corporation, USA); AmiconUltracel $30 \mathrm{~K}$ filters (Millipore Corporation, USA) and 96-well transparent microplates type 9018 (Costar, USA).

To manufacture immunochromatographic test systems an MDI easypack membrane set (Advanced Microdevices, India) was used including working nitrocellulose membranes CNPH90 on a polyester substrate, conjugate pad PT-R5, sample membrane FR1 (0.6) and upper adsorbing membranes AP045.

Obtaining recombinant SOD protein: Using the recombinant Escherichia coli BL21 (DE3)/pET22/SOD strain, $\mathrm{Cu} / \mathrm{Zn}$-dependent Superoxide Dismutase (SOD; molar weight $20.8 \mathrm{kDa}$ ) was obtained. A strain of the producer was obtained on the basis of $E$. coli BL21 (DE3) by transforming it with the original plasmid vector pET22/SOD.

The preparation and purification of the recombinant protein was performed according to the method described by Manat et al. (2014). E. coli BL21 (DE3) cells transformed with the $\mathrm{pET} 22 / \mathrm{SOD}$ plasmid were grown on solid LB/ampicillin plates $(100 \mu \mathrm{g} / \mathrm{mL})$ at $37^{\circ} \mathrm{C}$ overnight. One colony was selected for growing $5 \mathrm{~mL}$ of the starting culture overnight at $37^{\circ} \mathrm{C}$. The initial culture was inoculable in $500 \mathrm{~mL}$ of LB/ampicillin $(100 \mu \mathrm{g} / \mathrm{mL})$ and incubated at $37^{\circ} \mathrm{C}$ with shaking to an optical density of 0.6 at $600 \mathrm{~nm}$. Expression of recombinant SOD was induced by adding Isopropyl ${ }^{\circ}-\mathrm{D}-1$-Thiogalactopyranoside (IPTG) to a final concentration of $1 \mathrm{mM}$. Expression continued for $12 \mathrm{~h}$ at $37^{\circ} \mathrm{C}$. Cells were harvested by centrifugation.

The suspension of bacterial cells was sonicated for 10 mins with a pulse interval of $8 \mathrm{sec}$. The sonicate extract was centrifuged at $18,600 \mathrm{~g}$ for $30 \mathrm{~min}$ at $4^{\circ} \mathrm{C}$. The supernatant and cell pellet were analyzed using $12 \%$ SDS-PAGE. The recombinant protein was purified on a HisTrap column using a Ni-NTA Agarose chromatographic system. As a result, pure preparations of recombinant SOD of Brucella were obtained. The yield of the final product was $8 \mathrm{mg}$ from $1 \mathrm{~L}$ of induced culture.

Conjugation of proteins with QDs: Protein G was conjugated with QDs (core/shell CdSe/ZnS with excitation wavelength at $585 \mathrm{~nm}$ ) in accordance with Berlina et al. (2013) with partial modifications. The $300 \mu \mathrm{L}$ protein $\mathrm{G}$ in $10 \mathrm{mM}$ borate buffer solution ( $\mathrm{pH} 8.6$ ) with concentration $144 \mu \mathrm{g} / \mathrm{mL}$ was mixed with $25 \mu \mathrm{L}$ QDs $(8 \mu \mathrm{M}$ concentration) with carboxyl groups on the surface (QDs 585 ITK) at a molar ratio of $10: 1$. The $50 \mu \mathrm{L}$ each of the freshly prepared EDC and NHS solutions (with concentrations of 308 and $348 \mu \mathrm{g} / \mathrm{mL}$, respectively) were 
then added to the mixture of protein G and QDs. The reaction was performed in the dark at room temperature for a duration of $2 \mathrm{~h}$ while being stirred on an Intelli-Mixer RM-2 shaker (ELMI, Latvia). After this, the resulting conjugate was concentrated and simultaneously dialyzed against $10 \mathrm{mM}$ borate buffer solution with the use of Amicon Ultracel $30 \mathrm{~K}$ filters at $10,000 \mathrm{~g}$ for $15 \mathrm{~min}$ to remove excess activators and unbound protein. The centrifugation process was repeated 3 times and the total volume of the conjugate was decreased 10 times by the end of the cleansing procedure. The preparation was kept at $+4^{\circ} \mathrm{C}$ before application.

The conjugate of SOD was synthesized in a similar way. About $16 \mu \mathrm{L}$ of SOD in $20 \mathrm{mM}$ HEPES solution $(\mathrm{pH} 7.4)$ at a concentration of $2.7 \mathrm{mg} / \mathrm{mL}$ was diluted in $284 \mu \mathrm{L}$ HEPES and mixed with $25 \mu \mathrm{L}$ QDs $(8 \mu \mathrm{M})$ at a molar ratio of $10: 1 ; 50 \mu \mathrm{L}$ each of the same activator solutions were then added to the reaction mixture and kept for $2 \mathrm{~h}$ in the dark under constant stirring. The cleansing and concentrating steps were the same described above except the buffer solution for washing and storage which was $20 \mathrm{mM}$ HEPES instead of $10 \mathrm{mM}$ borate buffer.

Panel of cattle blood sera: A panel of characterized serum of cows infected with B. abortus and healthy animals was provided by the Republican State Enterprise "National Center for Biotechnology" under the Science Committee of Ministry of Education and Science of the Republic of Kazakhstan. The diagnosis of Brucellosis was estimated on the basis of data obtained using a commercial Enzyme Immuno Assay (ELISA) Kit manufactured by Bitsentr (Kazakhstan).

Detection of specific antibodies to SOD B. achas in cattle sera by ELISA: The sorption of SOD preparation in the wells of a 96-well microplate was carried out overnight at $4^{\circ} \mathrm{C}$ from $100 \mu \mathrm{L}$ of a solution with a concentration of $1 \mu \mathrm{g} / \mathrm{mL}$ in $50 \mathrm{mM}$ carbonate buffer, $\mathrm{pH}$ 9.6. The microplate was washed 4 times with $50 \mathrm{mMK}$-phosphate buffer, $\mathrm{pH} 7.4$ with $0.1 \mathrm{M} \mathrm{NaCl}$ and $0.05 \%$ Triton X-100 (PBST). After this $100 \mu \mathrm{L}$ of sera diluted with PBST from 1:100-1:100,000 was added into the wells as part of step 2 and incubated for $1 \mathrm{~h}$ at $37^{\circ} \mathrm{C}$. The microplate was then washed again $100 \mu \mathrm{L}$ of peroxidase-labeled antibodies against cattle $\operatorname{IgG}$ in PBST was then added at a concentration of $160 \mathrm{mg} / \mathrm{mL}$ and incubated for $1 \mathrm{~h}$ at $37^{\circ} \mathrm{C}$. After washing the microplate 3 times with PBST and once with distilled water, the peroxidase activity of the enzyme bound to the carrier was determined. For this purpose, $100 \mu \mathrm{L}$ substrate solution of 3,3', 5,5'-Tetramethylbenzidine (TMB) $0.42 \mathrm{mM}$ with $0.01 \%$
$\mathrm{H}_{2} \mathrm{O}_{2}$ was added to the wells and incubated for $15 \mathrm{~min}$ at room temperature the optical density at $450 \mathrm{~nm}$ (D450) was then measured.

Production of immunochromatographic test systems: IsoFlow dispenser (Imagene Technology, USA) was used to apply the reagents. Conjugates of QD with protein $\mathrm{G}$ (in scheme 1) and with SOD (in schemes 2 and 3) were applied to a membrane for the conjugate at a concentration of $34 \mu \mathrm{M}$ with a deposition volume of $1 \mu \mathrm{L} / \mathrm{mm}$ of membrane. To form an analytical zone, SOD (in schemes 1 and 2) or protein $\mathrm{G}$ (in Scheme 3) $0.1 \mu \mathrm{L} / \mathrm{mm}$ of protein concentration $2 \mathrm{mg} / \mathrm{mL}$ was applied on a nitrocellulose membrane CNPH90. After applying the reagents, the membranes were dried in air at $20-22^{\circ} \mathrm{C}$ for at least $20 \mathrm{~h}$. A multimembrane composite was collected and test strips $3.5 \mathrm{~mm}$ wide were obtained using an Index Cutter-1 automatic guillotine cutter (A-Point Technologies, USA). Cutting and packaging was carried out at $20-22^{\circ} \mathrm{C}$ in a special room with a relative humidity of not more than $30 \%$. The packed test strips were stored at $20-22^{\circ} \mathrm{C}$.

Immunochromatographic analysis: IC was carried out at room temperature. One drop of blood serum was applied to Eppendorf $500 \mu \mathrm{L}$ tube, 3 drops of $50 \mathrm{mM} \mathrm{K}$-phosphate buffer $(\mathrm{pH} 7.4)$ containing $0.1 \mathrm{M} \mathrm{NaCl}$ and $1 \%$ Tween-20 were added and the test strip was placed vertically into Eppendorf $500 \mu \mathrm{L}$ tube. After $10 \mathrm{~min}$, the result of the IC was fixed. The results of the QD-based IC were recorded by photographing the images of test strips when they were irradiated with UV light with a wavelength of $365 \mathrm{~nm}$. To quantify the signal intensity in the analytical zone of the test, the obtained photographs were digitized using the TotalLab TL120 software package (Nonlinear Dynamics, UK).

\section{RESULTS AND DISCUSSION}

Characterization of QD-protein conjugates: Water-soluble QD preparations consisting of a semiconductor core, a metal shell and a hydrophilic polymer coating were used. This label can be detected on the test working membrane at a concentration an order of magnitude lower than the traditionally used nano-sized gold. The sensitivity of IC with QDs, therefore, usually exceeds the sensitivity of tests with gold nanoparticles (Bruno, 2014; Shen et al., 2015; Taranova et al., 2017).

The synthesis of QD-protein conjugates was carried out using the carbodiimide-succinimide method including the activation of carboxyl groups of QD and the conjugation of the protein through the amino groups. 


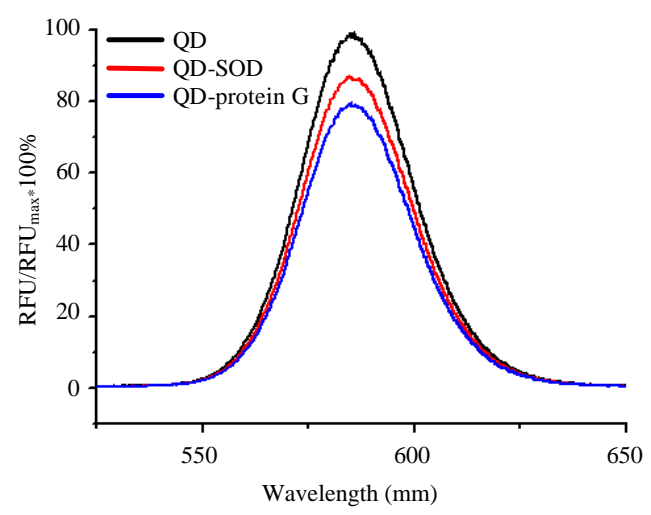

Fig. 2: Fluorescence spectra of QDs before and after conjugation with SOD of B. abortus and protein $\mathrm{G}$ Streptococcus spp. The QD concentration is $34 \mu \mathrm{M}$

The ratio of protein amounts per particle QD was 10:1. The resulting QD-SOD conjugates were purified by centrifugation through Amicon Ultracel $30 \mathrm{k}$ filters. In solutions that passed through the pores of the filters, no fluorescence was observed, indicating a complete separation of the conjugated QD from the reaction medium.

An important property of QD conjugates is the preservation of the fluorescent properties of the label. The formation of a protein coat on the particle surface partially shields the light absorbed and emitted by the QD. Therefore, after the conjugate synthesis, we checked the degree of conservation of the quantum yield of the fluorescence of the particles. Figure 2 shows the fluorescence spectra of free and conjugated nanoparticles. It can be seen that the decreases in the peak fluorescence amplitude of the conjugate of relatively free particles for the conjugates of SOD and protein $G$ are 12 and $20 \%$, respectively. In this case, the position of the fluorescence peak of the QD conjugate at $585 \mathrm{~nm}$ coincides with the peak of free QD. This indicates an absence of the effect of the cohesive protein on the electronic shells that determine the fluorescence of QD. Thus, covalently bound proteins do not cause significant changes in the fluorescent properties of the marker which makes it possible to effectively use the synthesized conjugates in the analysis.

Testing of sera by ELISA: A panel of bovine sera consisting of 5 positive and 5 negative samples was used to compare the possibilities of detecting specific immunoglobulins in 3 variants of IC. Cow serum was obtained from a livestock farm in the Republic of Kazakhstan. The presence or absence of specific

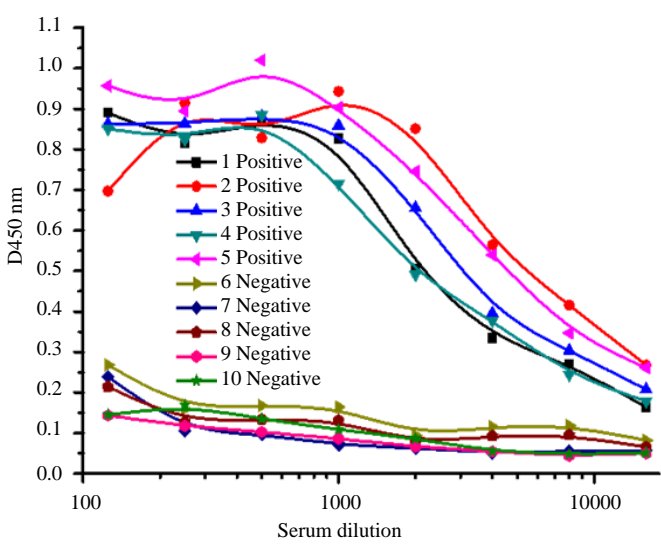

Fig. 3: ELISA testing of the control panel of cow blood sera on recombinant antigen SOD of B. abortus. 1-5: serum of cows with Brucellosis 6-10: serum of healthy cows

As an alternative antigen was used in our research (the SOD protein of B. abortus), the provided panel of sera was further characterized by ELISA to determine antibody titers against SOD and to confirm the diagnosis. The results of the enzyme immunoassay are shown in Fig. 3.

According to the ELISA results of all infected animals, the diagnosis was confirmed. When testing the blood sera of healthy animals, the ELISA signal did not exceed the threshold level of 0.2 optical units when the serum was diluted 500 times. Diagnostic titers of specific antibodies in positive sera ranged from 2000-5000 with an optical density in ELISA of D450 $=0.5$. The characterized panel of cattle blood sera was further used to compare the effectiveness of the detection of specific antibodies in IC.

Approbation of manufactured IC test systems: As noted in the introduction, immunochromatographic serodiagnosis using QD is currently tested in only one of 3 possible serodiagnosis schemes. The task of our study included a comparative assessment of the effectiveness of the use of QD in IC serodiagnosis in 3 different schemes for the implementation of the analysis. To achieve these goals, 3 series of tests were manufactured according to schemes 1-3 (Fig. 1).

The results of blood sera testing in the $3 \mathrm{IC}$ schemes are shown in Fig. 4. The value of the analytical signal increases in the series, e.g., scheme 1-3. When testing the sera of healthy cows, no positive response was observed, which indicates the specificity of the interaction. As an example, Fig. 4 shows the result of testing one of the negative sera (No. 6). The relative color intensities of the analytic zones are shown in Table 1. This demonstrates 


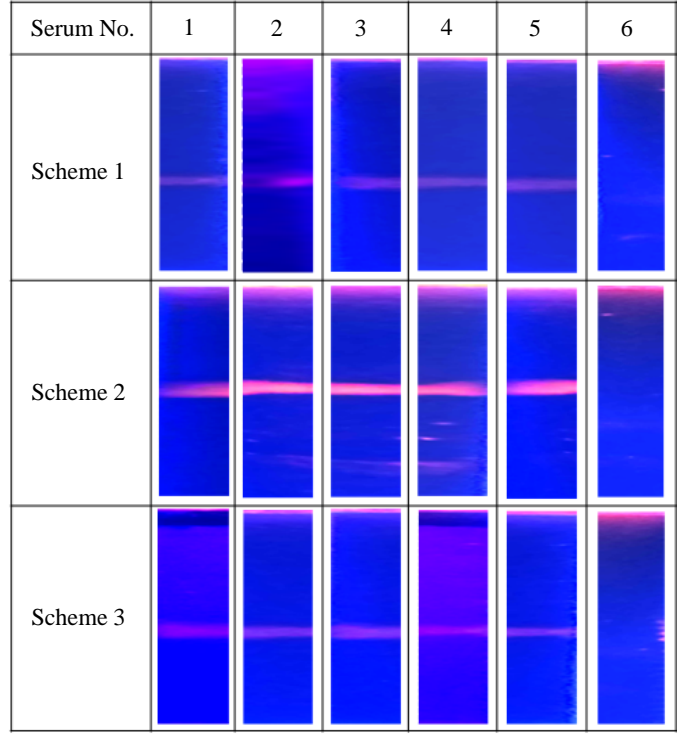

Fig. 4: Images of the working membranes of the test systems after carrying out IC under irradiation with $365 \mathrm{~nm}$ ultraviolet light

Table 1: Relative color intensities of the analytical zones of the test strips presented in Fig. 4

\begin{tabular}{lccc}
\hline Serum No. & Scheme 1 & Scheme 2 & Scheme 3 \\
\hline 1 & 18.7 & 71.2 & 31.9 \\
2 & 40.2 & 96.6 & 36.3 \\
3 & 29.9 & 90.4 & 43.9 \\
4 & 21.0 & 79.9 & 21.1 \\
5 & 24.0 & 98.0 & 26.7 \\
6 & 0 & 0 & 0 \\
\hline
\end{tabular}

that scheme 3 , on average, gives $16 \%$ more color intensity than scheme 1. As was shown in a number of papers (Ben-Selma et al., 2011; Martinez-Sernandez et al., 2011; Sotnikov et al., 2015a, b) in some cases scheme 3 allows for increased sensitivity. However, by Sotnikov et al. (2018), amplification was not always achieved and strongly depended on an uncontrolled parameter the constant of antibody-antigen interaction.

Thus, the differences in sensitivity in schemes 1 and 3 are random, although in most cases, scheme 3 allows for higher sensitivity. At the same time, scheme 2 gives on average a threefold increase in the fluorescence intensity in analytical zone compared to schemes 1 and 3 .

In our opinion, the reason for this is as follows. Schemes 1 and 3 suggest the interaction of all immunoglobulins from the sample with an immunoglobulin-binding reagent (usually an anti-species antibody such as protein a from Staphylococcus aureus or protein G from Streptococcus spp.). However, only a small portion of immunoglobulins interact specifically with the antigen which usually does not exceed $1 \%$ of the total concentration of immunoglobulins in the blood (Goldammer et al., 2002; Kemper et al., 2002; Turner et al., 2013; Tuerlinckx et al., 2014). Thus, the signal of the IC analysis in schemes 1 and 3 depends not only on the concentration of specific antibodies but also on the total content of immunoglobulins in the sample which is not a diagnostically significant parameter. Competition between specific and common immunoglobulins for binding to an immunoglobulin-binding protein adversely affects the reliability of analysis. Scheme 2 avoids this drawback as only specific antibodies are involved in the formation of detectable complexes. In addition, scheme 2 allows for the detection of specific immunoglobulins of all classes in serum while schemes 1 and 3 mainly detect class G immunoglobulins as the most commonly used immunoglobulin-binding proteins have lower affinity for other classes of immunoglobulins (Sidorin and Solov'eva, 2011; Boyle, 2014).

The 3 schemes for the implementation of IC serodiagnosisas an example of determining specific antibodies against superoxide dismutase of Brucella abortus are discussed in this study. The approbation of the test systems on a sample of cows with Brucellosis showed that the scheme with the use of antibody polyvalence (scheme 2) provided on average a threefold increase in signal compared to scheme 1 and 3 .

This is consistent with theoretical ideas about the possibilities of increasing sensitivity in different IC schemes. The greatest enhancement demonstrated in scheme 2 is probably due to the elimination of the interfering influence of common immunoglobulins on the assay results as well as the possibility of the simultaneous detection of immunoglobulins of all classes in this scheme.

\section{ACKNOWLEDGEMENT}

This study was financially supported by the Ministry of Science and Education of the Russian Federation (grant agreement No. 14.613.21.0080 on 22.11.2017, unique identifier RFMEFI61317X0080)

\section{REFERENCES}

Abdoel, T., I.T. Dias, R. Cardoso and H.L. Smits, 2008. Simple and rapid field tests for Brucellosis in livestock. Vet. Microbiol., 130: 312-319.

Ben-Selma, W., H. Harizi and J. Boukadida, 2011. Immunochromatographic $\mathrm{IgG/IgM}$ test for rapid diagnosis of active tuberculosis. Clin. Vaccine Immunol., 18: 2090-2094. 
Berlina, A.N., N.A. Taranova, A.V. Zherdev, M.N. Sankov and I.V. Andreev et al., 2013. Quantum-dot-based immunochromatographic assay for total $\operatorname{IgE}$ in human serum. PloS One, 8: 1-8.

Boyle, M.D., 2014. Bacterial Immunoglobulin-Binding Proteins: Applications in Immunotechnology. 1stEdn., Elsevier Publishing, Amsterdam, Netherlands, ISBN:9781483216539, Pages: 494.

Bricker, B.J., L.B. Tabatabai, B.A. Judge, B.L. Deyoe and J.E. Mayfield, 1990. Cloning, expression and occurrence of the Brucella $\mathrm{Cu}-\mathrm{Zn}$ superoxide dismutase. Infect. Immun., 58: 2935-2939.

Bruno, J.G., 2014. Application of DNA aptamers and quantum dots to lateral flow test strips for detection of foodborne pathogens with improved sensitivity versus colloidal gold. Pathog., 3: 341-355.

De Puig, H., I. Bosch, L. Gehrke and K. Hamad-Schifferli, 2017. Challenges of the nano-bio interface in lateral flow and dipstick immunoassays. Trends Biotechnol., 35: 1169-1180.

Goldammer, A., K. Derfler, K. Herkner, A.R. Bradwell and W.H. Horl et al., 2002. Influence of plasma immunoglobulin level on antibody synthesis. Blood, 100: $353-355$

Goldman, E.R., I.L. Medintz and H. Mattoussi, 2006. Luminescent quantum dots in immunoassays. Anal. Bioanal. Chem., 384: 560-563.

Janwan, P., P.M. Intapan, H. Yamasaki, R. Rodpai and P. Laummaunwai et al., 2016. Development and usefulness of an immunochromatographic device to detect antibodies for rapid diagnosis of human gnathostomiasis. Parasites Vectors, 9: 1-14.

Junior, G.N., J. Megid, L.A. Mathias, L. Paulin and A.F. Vicente et al., 2017. Performance of microbiological, serological, molecular and modified seminal plasma methods in the diagnosis of Brucella abortus in semen and serum of bovine bulls. Biol., 48: 6-9.

Karakus, C. and B.A. Salih, 2013. Comparison of the Lateral Flow Immunoassays (LFIA) for the diagnosis of Helicobacter pylori infection. J. Immunol. Meth., 396: 8-14.

Kemper, M.J., H. Altrogge, R. Ganschow and D.E. Muller-Wiefel, 2002. Serum levels of immunoglobulins and $\operatorname{IgG}$ subclasses in steroid sensitive nephrotic syndrome. Pediatr. Nephrol., 17: 413-417.

Lode, P.V., 2005. Point-of-care immunotesting: Approaching the analytical performance of central laboratory methods. Clin. Biochem., 38: 591-606.

Manat, Y., A.V. Shustov, G.B. Unyshiva, N.I. Sarina and S.Z. Eskendirova, 2014. Production, purification and characterization of recombinant $\mathrm{Cu} / \mathrm{Zn}$ superoxide dismutase of Brucella abortus. Chin. J. Anim. Infect. Dis., 22: 46-51.
Martinez-Sernandez, V., L. Muino, M.J. Perteguer, T. Garate and M. Mezo, 2011. Development and evaluation of a new lateral flow immunoassay for serodiagnosis of human fasciolosis. PLoS Negl. Trop. Dis., 5: 1-7.

Minda, A.G. and M.K. Gezahegne, 2016. A review on diagnostic methods of Brucellosis. J. Vet. Sci. Technol., 7: 1-8.

Nakano, S., T. Tsukimura, T. Togawa, T. Ohashi and M. Kobayashi et al., 2015. Rapid immunochromatographic detection of serum anti$\alpha$-galactosidase: A antibodies in Fabry patients after enzyme replacement therapy. PloS One, 10: 1-12.

Parija, S.C., 2014. Textbook of Microbiology and Immunology. 2nd Edn., Elsevier, Amsterdam, Netherlands, ISBN:9788131236246, Pages: 684.

Quesada-Gonzalez, D. and A. Merkoci, 2015. Nanoparticle-based lateral flow biosensors. Biosens. Bioelectron., 73: 47-63.

Rajerison, M., S. Dartevelle, L.A. Ralafiarisoa, I. Bitam and D.T.N. Tuyet et al., 2009. Development and evaluation of two simple, rapid immunochromatographic tests for the detection of Yersinia pestis antibodies in humans and reservoirs. PLoS Negl. Trop. Dis., 3: 1-7.

Ryan, K.J., C.G. Ray and J.C. Sherris, 2004. Sherris Medical Microbiology: An Introduction to Infectious Diseases. 4th Edn., McGraw Hill, New York, USA., ISBN-13: 9780838585290 , Pages: 979.

Sato, N.S., C.S.D. Melo, L.C. Zerbini, E.P. Silveira and L.J. Fagundes et al., 2003. Assessment of the rapid test based on an immunochromatography technique for detecting anti-Treponema pallidum antibodies. Rev. Inst. Med. Trop. Sao Paulo, 45: 319-322.

Schrier, W.H., R.J. Schoengold, J.T. Baker, J.L. Norell and C.L. Jaseph et al., 1998. Development of FlexSureß HP-an immunochromatographic method to detect antibodies against Helicobacter pylori. Clin. Chem., 44: 293-298.

Shen, J., Y. Zhou, F. Fu, H. Xu and J. Lv et al., 2015. Immunochromatographic assay for quantitative and sensitive detection of hepatitis $B$ virus surface antigen using highly luminescent quantum dotbeads. Talanta, 142: 145-149.

Sidorin, E.V. and T.F. Soloveva, 2011. IgG-binding proteins of bacteria. Biochem. Moscow, 76: 295-308.

Sotnikov, D.V., A.V. Zherdev and B.B. Dzantiev, 2018. Theoretical and experimental comparison of different formats of immunochromatographic serodiagnostics. Sens., 18: 1-15.

Sotnikov, D.V., A.V. Zherdev, V.G. Avdienko and B.B. Dzantiev, 2015b. Immunochromatographic assay for serodiagnosis of tuberculosis using an antigen-colloidal gold conjugate. Appl. Biochem. Microbiol., 51: 834-839. 
Sotnikov, D.V., N.A. Byzova, A.V. Zherdev, S.Z. Eskendirova and K.K. Baltin et al., 2015a. Express immunochromatographic detection of antibodies against Brucella Abortus in cattle sera based on quantitative photometric registration and modulated cut-off level. J. Immunoassay Immunochem., 36: 80-90.

Stevens, M.G., L.B. Tabatabai, S.C. Olsen and N.F. Cheville, 1994. Immune responses to superoxide dismutase and synthetic peptides of superoxide dismutase in cattle vaccinated with Brucella abortus strain 19 or RB51. Vet. Microbiol., 41: 383-389.

Struyf, F., A. Lemmens, E. Valadas, J. Verhaegen and M. Van Ranst, 1999. Usefulness of immunochromatographic detection of antibodies to Mycobacterium tuberculosis as an adjunct to auramine staining for rapid diagnosis of tuberculosis in a low-prevalence setting. Eur. J. Clin. Microbiol. Infect. Dis., 18: 740-742.

Tabatabai, L.B. and S.G. Hennager, 1994. Cattle serologically positive for Brucella abortus have antibodies to $B$. abortus $\mathrm{Cu}-\mathrm{Zn}$ superoxide dismutase. Clin. Diagn. Lab. Immunol., 1: 506-510.

Taranova, N.A., A.N. Berlina, A.A. Semeykina, A.V. Zherdev and B.B. Dzantiev, 2017. Comparative characteristics of nanodisperse labels for immunochromatographic test systems. Nano Hybrids Compos., 13: 32-38.

Taranova, N.A., A.N. Berlina, A.V. Zherdev and B.B. Dzantiev, 2015. Traffic light immunochromatographic test based on multicolor quantum dots for the simultaneous detection of several antibiotics in milk. Biosens. Bioelectron., 63: 255-261.
Tille, P., 2015. Bailey and Scotts Diagnostic Microbiology. Elsevier Health Sciences, Amsterdam, Netherlands, ISBN:9780323428927,.

Tuerlinckx, D., B. Florkin, A. Ferster, I.D. Schutter and C. Chantrain et al., 2014. Pneumococcal antibody levels in children with PID receiving immunoglobulin. Pediatr., 133: e154-e162.

Turner, P., C. Turner, N. Green, L. Ashton and E. Lwe et al., 2013. Serum antibody responses to pneumococcal colonization in the first 2 years of life: Results from an SE Asian longitudinal cohort study. Clin. Microbiol. Infect., 19: E551-E558.

Vrublevskaya, V.V., V.N. Afanasyev, A.A. Grinevich, Y.Y. Skarga and P.P. Gladyshev et al., 2017. A sensitive and specific lateral flow assay for rapid detection of antibodies against glycoprotein B of Aujeszky's disease virus. J. Virological Meth., 249: $175-180$.

Wang, C., F. Hou and Y. Ma, 2015. Simultaneous quantitative detection of multiple tumor markers with a rapid and sensitive multicolor quantum dots based immunochromatographic test strip. Biosens. Bioelectron., 68: 156-162.

Wong, R. and H. Tse, 2009. Lateral Flow Immunoassay. Humana Press, New York, USA., Pages: 223.

Wu, H.S., S.C. Chiu, T.C. Tseng, S.F. Lin and J.H. Lin et al., 2004. Serologic and molecular biologic methods for SARS-associated coronavirus infection, Taiwan. Emerging Infect. Dis., 10: 305-310.

Yang, H., D. Li, R. He, Q. Guo and K. Wang et al., 2010. A novel quantum dots-based point of care test for syphilis. Nanoscale Res. Lett., 5: 875-881. 